\title{
Preface: Special Issue on Dynamic Games in Macroeconomics
}

\author{
Edward C. Prescott ${ }^{1}$. Kevin L. Reffett ${ }^{1}$
}

Published online: 12 January 2016

C) Springer Science+Business Media New York 2016

Many important questions in macroeconomics can be formulated as a dynamic game. For example, in dynamic general equilibrium models with public policy, where policymakers face a common agreed upon social objective, the optimal plans of the current government can fail to be time consistent (e.g., Kydland and Prescott [15] and Barro and Gordon [8]). This time inconsistency problem can be studied as a constrained optimization problem with forward- or backward-looking endogenous constraints on an enlarged state space (e.g., see Kydland and Prescott [16], Rustichini [27], Marcet and Marimon [21], or Feng et al. [13]), or as a dynamic game (i.e., Pollak [26], Peleg and Yaari [23], Phelan and Stacchetti [24]). A related situation arises when households make consumption-savings decisions and their intertemporal preferences are dynamically inconsistent. This problem was first studied in Strotz [29] and Pollak [26] and has been the focus of an extensive literature in macroeconomics (e.g., see Laibson [17] and Bernheim et al. [10]). Yet another prototype dynamic game in macroeconomics arises in altruistic models of economic growth where the dynastic choice problem between generations is a strategic one. Models in this spirit were first introduced in Phelps and Pollak [25] and subsequently studied in Bernheim and Ray [9], Leininger [18], Amir [3], and Balbus et al. [5,6], among others. One additional prototype of a dynamic games and strategic interactions in macroeconomics occurs in models of endogenous borrowing constraints and sustainable debt (e.g., Chari and Kehoe [11] and Alvarez and Jermann [4]).

This special issue of Dynamic Games and Applications collects recent papers providing new results on the existence, characterization, and the computation of dynamic equilibria in macroeconomic models with strategically interacting agents. The volume contains work in both dynamic and stochastic games. In the paper by Messner and Pavoni [22], the authors reconsider the nature of the solutions to incentive-constrained dynamic programs generated by recursive saddlepoint methods pioneered in the work of Marcet and Marimon [21].

Kevin L. Reffett

Kevin.reffett@asu.edu

Edward C. Prescott

Edward.Prescott@asu.edu

1 Department of Economics, WP Carey School of Business, Arizona State University,

Tempe, AZ, USA 
These methods have found extensive application in the literature over the last two decades on dynamic models with limited commitment and strategic interaction. The paper shows that even under the best of case (i.e., the incentive-constrained dynamic programs remain convex, saddlepoints exist, and strong duality is present), the recursive saddlepoint method can provide solutions that are not primal feasible optimal and suboptimal.

Two papers in the volume consider strategic dynamic programming as an alternative to recursive saddlepoint methods for computing dynamic equilibria in games. These methods can be viewed as set-valued primal formulations of incentive-constrained dynamic programming methods, and were pioneered for repeated games by Abreu et al. (henceforth APS, $[1,2])$. In this volume, the methods are extended to the setting of dynamic and/or a stochastic game. When these methods can be applied, one obtains characterization of equilibrium values of all the subgame perfect equilibria in the games relative to the equilibrium concept imposed (e.g., subgame perfect, Markov perfect). ${ }^{1}$

It is well known that computing the equilibrium value set can be a serious complication of implementing strategic dynamic programming methods. In the paper of Sleet of Yeltekin [28], the authors discuss how APS methods can be applied to interesting classes of dynamic games and then provide a new method for computing equilibrium value correspondences. The authors new method is based on outer and inner approximations of the equilibrium value correspondence via step-valued set functions. The new methods are related to the methods used in the paper by Feng and Dominguez [12] to compute optimal time-consistent solutions for dynamic general equilibrium models with public policy.

In the paper of Balbus and Woźny [7], the authors extend APS methods to the study of the equilibrium value set generated by Markov perfect Nash equilibrium (MPNE) in a class of stochastic games with uncountable state spaces. In their methods, the equilibrium value correspondence is generated by short-memory nonstationary equilibrium Markov decision processes. The authors then show how to apply these methods to the problem of subgame perfect equilibrium in dynamic models where agents possess dynamically inconsistent preference (e.g., models with quasihyperbolic agents).

In the paper by Fesselmeyer et al. [14], the authors study a Cournot-Nash equilibrium in an important class of one-sector growth models with strategic interactions and externalities. Their model studies the case of strategic interaction between agents over dynamic consumption and investments in a world with technical progress. Specializing the primitives of their model in a similar vein as used in the seminal paper of Levhari and Mirman [19], the authors are able to obtain sharp closed-form characterizations of Markovian equilibrium in this class of models.

Two papers of the volume study prototype time-consistency problems as they arise in dynamic general equilibrium models in macroeconomics. In the paper by Feng and Dominguez [12], the authors study the time-consistency problem of labor taxes in a dynamic economy without capital taxes. The environment is very closely related to the Ramsey taxation setting studied in the paper of Phelan and Stachetti [24], a prototype time-consistency problem in the spirit of Kydland and Prescott $[15,16]$. But in their paper, the emphasis is on the structure of time- consistent labor taxes (as opposed to capital taxes).

In the paper by Malair and Malair [20], the authors consider the question of computing time-consistent equilibrium solutions for models where agents possess dynamically inconsistent preferences (the prime example being the so-called $\beta-\delta$ models with quasihyperbolic

\footnotetext{
1 In the original APS methods, the value correspondence was constructed for subgame perfect equilibrium. But as the paper of Balbus and Woźny [7] in this volume shows, one can consider shorter memory constructions (e.g., using nonstationary minimal state space Markov perfect equilibria).
} 
agents). In particular, they show that generalized Euler equation methods that have been applied extensively in this literature generate a continuum of equilibrium solutions, each characterized by a different constant of integration. Then, they develop an endogenous grid method (based on backward value function induction) where the limit of the finite horizon solution converges to a limiting solution for the infinite horizon case.

We are grateful to the Editor-in-Chief of the DGAA, Georges Zaccour, for his commitment to a special volume on dynamic games in macroeconomics, inviting us to serve as its guest editors of this journal, and providing expert advice on the editorial process. We also would also like to thank all the reviewers for their input on submitted papers, the contributors to this volume for submitting their work, as well as the editorial group at Springer for helping us with the logistical details of this project.

\section{References}

1. Abreu D, Pearce D, Stacchetti E (1986) Optimal cartel equilibria with imperfect monitoring. J. Econ Theory 39:251-269

2. Abreu D, Pearce D, Stacchetti E (1990) Toward a theory of discounted repeated games with imperfect monitoring. Econometrica 58:1041-1063

3. Amir R (1996) Strategic intergenerational bequest with stochastic convex production. Econ Theory 8:367376

4. Alvarez F, Jermann U (2000) Efficiency, equilibrium, and asset pricing with risk of default. Econometrica 68:775-797

5. Balbus L, Reffett K, Woźny L (2012) Stationary Markov equilibria in stochastic OLG models with limited commitment. J Math Econ 48:115-132

6. Balbus L, Reffett K, Woźny L (2013) A constructive geometrical approach to uniqueness of Markov stationary equilibrium in stochastic games of intergenerational altruism. J Econ Dyn Control 37:10191039

7. Balbus L, Woźny L (2015). Strategic dynamic programming methods for short memory equilibria in a class of stochastic games with uncountable state spaces. Dyn Games Appl, this volume

8. Barro R, Gordon D (1983) Rules, discretion, and reputation in a model of monetary policy. J Monet Econ 12:101-121

9. Bernheim D, Ray D (1983) Altruistic growth economies. Stanford University, Stanford (unpublished manuscript)

10. Bernheim D, Ray D, Yeltekin S (2015) Poverty and self-control. Econometrica 83:1877-1911

11. Chari V, Kehoe P (1990) Sustainable plans. J Polit Econ 98:783-802

12. Feng Z, Dominguez B (2015) The time inconsistency problem of labor taxes and constitutional constraints. Dyn Games Appl, this volume

13. Feng Z, Miao J, Peralta-Alva A, Santos M (2014) Numerical solution of nonoptimal dynamic general equilibrium models. Int Econ Rev 55:83-110

14. Fesselmeyer E, Mirman L, Santugini M (2015) Strategic interactions in a one-sector growth model. Dyn Games Appl, this volume

15. Kydland F, Prescott EC (1977) Rules rather than discretion: the inconsistency of optimal plans. J Polit Econ 85:473-492

16. Kydland F, Prescott EC (1980) Dynamic optimal taxations, rational expectations, and optimal control. J Econ Dyn Control 2:79-91

17. Laibson D (1997) Golden eggs and hyperbolic discounting. Q J Econ 112:443-477

18. Leininger W (1986) The existence of perfect equilibria in a model of growth with altruism between generations. Rev Econ Stud 53:349-367

19. Levhari D, Mirman LJ (1980) The great fishwar: an example using a dynamic Cournot-Nash solution. Bell J Econ 11:322-334

20. Maliar L, Maliar S (2015) Ruling out multiplicity of smooth equilibria in dynamic games: a quasigeometric discounting example. Dyn Games Appl, this volume

21. Marcet A, Marimon R (2011) Recursive contracts. CEP Discussion Paper \#1055 (unpublished manuscript)

22. Messner M, Pavoni N (2015) On the recursive saddlepoint method. Dyn Games Appl, this volume

23. Peleg B, Yaari ME (1973) On the existence of a consistent plan of action when tastes are changing. Rev Econ Stud 40:391-401 
24. Phelan C, Stachetti E (2001) Sequential equilibria in a Ramsey tax model. Econometrica 69:1491-1518

25. Phelps E, Pollak R (1968) On second-best national savings and game-theoretic growth. Rev Econ Stud 35:185-199

26. Pollak R (1968) Consistent planning. Rev Econ Stud 35:201-208

27. Rustichini A (1998) Dynamic programming solutions to incentive constrained problems. J Econ Theory 78:329-354

28. Sleet C, Yeltekin S (2015) On the computation of value correspondences for dynamic games. Dyn Games Appl, this volume

29. Strotz R (1956) Myopia and inconsistency in dynamic utility maximization. Rev Econ Stud 23:165-180 